pag

Business School

WORKING PAPER SERIES

Working Paper 2014-299

\section{Testing the relationships between} energy consumption and income in G7 countries with nonlinear causality tests

Ahdi Noomen Ajmi

Ghassen El Montasser

Duc Khuong Nguyen

http://www.ipag.fr/fr/accueil/la-recherche/publications-WP.html

IPAG Business School

184, Boulevard Saint-Germain

75006 Paris

France 


\title{
Testing the relationships between energy consumption and income in G7 countries with nonlinear causality tests
}

\author{
Ahdi Noomen Ajmi ${ }^{\mathrm{a}, \mathrm{b}}$, Ghassen El Montasser ${ }^{\mathrm{a}}$, Duc Khuong Nguyen ${ }^{\mathrm{c}, *}$ \\ ${ }^{a}$ ESC de Tunis, Université de la Manouba, Manouba, Tunisia. \\ ${ }^{b}$ Laboratoire BESTMOD, ISG de Tunis, Univesité de Tunis, Tunisia. \\ ${ }^{c} I P A G$ Business School $\&$ University of Paris 1 Panthéon-Sorbonne, 184 Bld \\ Saint-Germain, 75006 Paris, France.
}

\begin{abstract}
Knowing the real causal links between energy consumption and national income is crucial for policy decision making. In this article, we address this issue for the G7 countries by using two nonlinear causality tests in the sense of Hiemstra and Jones (1994), and Kyrstou and Labys (2006). Our results reveal some new, but mixed results. Hiemstra-Jones test indicates unidirectional causality running from energy consumption to GDP for the United Kingdom, while a bidirectional causality between energy consumption and GDP is found for Canada, France, Japan and United States. On the other hand, Kyrstou-Labys test shows that unidirectional causality runs from energy consumption to GDP for France and the United States, and from GDP to energy consumption for Germany. Overall, our findings suggest that policy implications of the energy-GDP links should be interpreted with caution, given the test-dependent and country-specific results.
\end{abstract}

Keywords:

energy consumption; GDP; nonlinear causality

\footnotetext{
*Corresponding author

Email addresses: ajmi.ahdi.noomen@gmail.com (Ahdi Noomen Ajmi), ghassen.el-montasser@laposte.net (Ghassen El Montasser), duc.nguyen@ipag.fr (Duc Khuong Nguyen)
} 


\section{Introduction}

There has been now a long debate on the dynamic interactions between economic dynamics and energy sector. The majority of previous studies focus particularly on three important causal relationships: oil-macroeconomy nexus, oil-stock market nexus, and energy-growth nexus. A consesus arising from the past literature is that oil prices significantly affect economic growth, stock markets and exchange rates through different channels and with different degrees depending on the energy profile of individual countries and markets under consideration (e.g., Hamilton, 1983; Mork, 1989; Hooker, 1996; Cologni and Manera, 2008; Jammazi and Aloui, 2010; Aloui et al., 2012). Moreover, the effects of oil prices can be asymmetric, nonlinear and sensitive to market phases (e.g., Balke et al., 2002; Zhang, 2008; Lardic and Mignon, 2008; Cologni and Manera, 2009). For example, Hamilton (1983) shows that rising oil prices are responsible for nine out of ten of the U.S. recessions since the Second World War. Zhang (2008) employs a nonlinear model to investigate the relationship between oil-price shock and economic growth in Japan, and shows the existence of nonlinearities and asymmetric linkages between the two variables studied. Lardic and Mignon (2008) reach the same conclusion for other developed economies from an asymmetric cointegration approach. On the other hand, past studies have found that stock market activities are significantly affected by oil price movements at both the market and sectoral levels (Jones and Kaul, 1996; Sadorsky, 2001; Park and Ratti, 2008; Arouri and Nguyen, 2010; Fayyad and Daly, 2011). The oil's impact is however sensitively different across economic sectors (e.g., oil versus non-oil industries) and across countries (e.g., net oil-exporting versus net oil-importing ones).

As far as the causal relationship between energy consumption and economic growth is concerned, the recent literature survey by Ozturk (2010) shows that no consensus neither on the existence nor on the direction of causality between the two variables of interest emerge from the past literature. While some studies find some evidence of unidirectional causality running from energy consumption to growth (Stern, 2000; Oh and Lee, 2004; Wolde-Rufael, 2004; Ho and Siu, 2007), the others conclude on the unidirectional causalitity from growth to energy consumption (Zamani, 2007; Mehrara, 2007; Ang, 2008; Zhang and Cheng, 2009) or even no causality between these variables (Halicioglu, 2009; Payne, 2009). There is also evidence to support the bidirectional causality between energy consumption and 
growth (Glasure, 2002; Erdal et al., 2008; Belloumi, 2009). Mixed rerults are found in Soytas and Sari (2003), Lee (2006), Francis et al. (2007), Akinlo (2008), and Chiou-Wei et al. (2008), among others. Overall, past empirical results appear to be country-specific and more often than not divergent across studies.

Even though the above-mentioned conflicting results can be attributed to the different dataset, countries' characteristics, variables used and different econometric methods, the accurate modeling of the underlying data stands out. It can be observed that most of previous studies rely on traditional linear Granger causality tests to examine the interactions between energy consumption and growth, while energy and economic variables are rather tied up by nonlinear links. The potential nonlinearity, which casts doubt on the results from linear framework, has been confirmed by several studies in energy economics (Hamilton, 2003; Lee and Chang, 2007; Chiou-Wei et al., 2008; Huang et al., 2008; Rahman and Serletis, 2010). In an earlier study, Hiemstra and Jones (1994) report that economic time series exhibit nonlinear dependence that has not always been addressed properly.

In this article, we investigate the causal relationship between energy consumption and national income by adopting a nonlinear approach. We indeed apply two nonlinear causality tests in the sense of Hiemstra and Jones (1994) and Kyrstou and Labys (2006) to the data of the most advanced countries (G7 countries). The most important feature of these tests is that they enable to detect nonlinear causal relationships while avoiding problems arising from model misspecification. Hiemstra and Jones (1994) show from a simulation study that the modified version of their test is robust to a number of model misspecifications. Moreover, unlike nonlinear error correction models may display stability problems (Saikkonen, 2005), these tests permit to gauge nonlinear causality without being concerned by the long-term dynamics reflecting the evolution of this causality. The "asymmetric" causality test of Kyrstou and Labys (2006) is advantageous in that it can reveal interesting information about the inherent dynamics of the underlying data-generating processes. According to Hristu-Varsakelis and Kyrtsou (2008), the detection of a causality relationship does not give information on whether shocks are positive or negative, and conversely the lack of an apparent causality relationship does not preclude the existence of causality when we condition certain features, such as a positive or negative sign.

Following the seminal work of Kraft and Kraft (1978), a number of studies have examined the causal relationships between energy consumption and 
economic growth using data from the G7 countries. Table 1 shows that the empirical results of this strand of literature are also country-specific and often mixed. ${ }^{1}$ Our article thus contributes to the related literature by adding new evidence from more robust nonlinear causality tests. The results from Hiemstra-Jones test show unidirectional causality from energy consumption to GDP for the United Kingdom, while a bidirectional causality between energy consumption and GDP is found for Canada, France, Japan and the United States. On the other hand, Kyrstou-Labys test provides evidence of unidirectional causality from energy consumption to GDP for France and the United States, and from GDP to energy consumption for Germany. These new mixed findings imply that policy interpretations of the energy-GDP links from the results of both previous studies and ours should be done with caution and that a country-specific approach is better than a panel data one as the latter may induce compensation effects across different countries.

The remainder of the article is organized as follows. Section 2 will discuss some explanations for the use of nonlinear causality tests and introduces two nonlinear Granger causality tests proposed by Hiemstra and Jones (1994), and Krystou and Labys (2006). Section 3 reports and discusses the empirical results. Section 5 provides some concluding remarks.

\section{Nonlinearities and nonlinear Granger causality tests}

Granger (1969) defines causality between two variables $E$ and $Y$ in terms of predictability. ${ }^{2}$ Accordingly, a variable $E$ is said to cause another variable $Y$ with respect to the universe or information set including $E(t)=E_{t}, E_{t-1}, \ldots$ and $Y(t)=Y_{t}, Y_{t-1}, \ldots$ if $Y_{t+1}$ can be better predicted by using the information in $E(t)$ than by not doing so, all other relevant information (including the present and the past of $Y$ ) being used in either case. Specifically, the traditional approach for testing Granger causality compares the prediction errors obtained by a model that relates $Y$ to past and current values of both $E$ and $Y$. This approach is naturally attractive because the test simply requires to determine whether the regression model coefficients, associated to past and current values of $E$ are significant.

However, it is now common that the traditional Granger framework is exposed to two main drawbacks. First, parametric tests require several mod-

\footnotetext{
${ }^{1}$ See Ozturk (2010) for the detailed literature survey.

${ }^{2}$ In our study, $E$ and $Y$ denote energy consumption and income, respectively.
} 
Table 1: Summary of literature on energy consumption - economic growth nexus for G7 countries.

\begin{tabular}{|c|c|c|c|c|c|}
\hline Country & Author(s) & Causality & Country & Author(s) & Causality \\
\hline \multirow[t]{16}{*}{ USA } & Kraft and Kraft (1978) & $\mathrm{Y} \rightarrow \mathrm{E}$ & UK & Yu and Choi (1985) & $\mathrm{Y}-\mathrm{E}$ \\
\hline & Akarca and Long (1980) & $\mathrm{Y}-\mathrm{E}$ & & Erol and Yu (1987) & $\mathrm{Y}-\mathrm{E}$ \\
\hline & Yu and Hwang (1984) & $\mathrm{Y}-\mathrm{E}$ & & Lee (2006) & $\mathrm{Y}-\mathrm{E}$ \\
\hline & Yu and Choi (1985) & $\mathrm{Y}-\mathrm{E}$ & & Soytas and Sari (2006) & $\mathrm{Y} \longleftrightarrow \mathrm{E}$ \\
\hline & Abosedra and Baghestani (1989) & $\mathrm{Y} \rightarrow \mathrm{E}$ & & & \\
\hline & Yu and Jin (1992) & $\mathrm{Y}-\mathrm{E}$ & France & Erol and Yu (1987) & $\mathrm{Y}-\mathrm{E}$ \\
\hline & Stern (1993) & $\mathrm{E} \rightarrow \mathrm{Y}$ & & Soytas and Sari (2003) & $\mathrm{E} \rightarrow \mathrm{Y}$ \\
\hline & Cheng (1995) & $\mathrm{Y}-\mathrm{E}$ & & Lee $(2006)$ & $\mathrm{Y} \rightarrow \mathrm{E}$ \\
\hline & Stern (2000) & $\mathrm{E} \rightarrow \mathrm{Y}$ & & Soytas and Sari (2006) & $\mathrm{E} \rightarrow \mathrm{Y}$ \\
\hline & Soytas and Sari (2003) & $\mathrm{Y}-\mathrm{E}$ & & & \\
\hline & Lee $(2006)$ & $\mathrm{Y} \longleftrightarrow \mathrm{E}$ & Canada & Erol and Yu (1987) & $\mathrm{E} \rightarrow \mathrm{Y}$ \\
\hline & Soytas and Sari (2006) & $\mathrm{E} \rightarrow \mathrm{Y}$ & & Ghali and El-Sakka (2004) & $\mathrm{Y} \longleftrightarrow \mathrm{E}$ \\
\hline & Chiou-Wei et al. (2008) & $\mathrm{Y}-\mathrm{E}$ & & Lee $(2006)$ & $\mathrm{E} \rightarrow \mathrm{Y}$ \\
\hline & Bowden and Payne (2009) & $\mathrm{E} \rightarrow \mathrm{Y}$ & & Soytas and Sari (2006) & $\mathrm{Y} \longleftrightarrow \mathrm{E}$ \\
\hline & Payne (2009) & $\mathrm{Y}-\mathrm{E}$ & Italy & Erol and Yu (1987) & $\mathrm{Y} \rightarrow \mathrm{E}$ \\
\hline & & & & Soytas and Sari (2003) & $\mathrm{Y} \rightarrow \mathrm{E}$ \\
\hline \multirow[t]{6}{*}{ Japan } & Erol and Yu (1987) & $\mathrm{Y} \longleftrightarrow \mathrm{E}$ & & Lee $(2006)$ & $\mathrm{Y} \longleftrightarrow \mathrm{E}$ \\
\hline & Cheng (1998) & $\mathrm{Y} \rightarrow \mathrm{E}$ & & & \\
\hline & Soytas and Sari (2003) & $\mathrm{E} \rightarrow \mathrm{Y}$ & Germany & Erol and Yu (1987) & $\mathrm{Y} \rightarrow \mathrm{E}$ \\
\hline & Lee (2006) & $\mathrm{Y} \rightarrow \mathrm{E}$ & & Soytas and Sari (2003) & $\mathrm{E} \rightarrow \mathrm{Y}$ \\
\hline & Soytas and Sari (2006) & $\mathrm{Y} \longleftrightarrow \mathrm{E}$ & & Lee $(2006)$ & $\mathrm{Y} \rightarrow \mathrm{E}$ \\
\hline & & & & Soytas and Sari (2006) & $\mathrm{Y} \rightarrow \mathrm{E}$ \\
\hline
\end{tabular}

Note: $\mathrm{Y}=$ GDP, $\mathrm{E}=$ energy consumption. $\rightarrow, \leftrightarrow,-$ represent unidirectional causality, bidirectional causality and no causality, respectively. 
eling assumptions among which the most important is the linearity of the regression structure, while the nonlinearity of macroeconomic and financial series is becoming increasingly recognized by economists. Nonlinear models are thus more appropriate for modeling dependencies among economic variables. Second, the prediction errors from linear Granger causality tests are ultimately sensitive to the causality in the mean. Higher order structure, such as conditional heteroscedasticity, is often ignored. In this article, we address the first drawback by making use of two nonlinear Granger causality tests. The first, that of Hiemstra and Jones (1994), is nonparametrically conceived and based on correlation integrals, while the second, that of Krystou and Labys (2006), is based on a parametric model.

\subsection{Hiemestra-Jones test}

Baek and Brock (1992) offer a nonparametric statistical method to detect nonlinear causal relations. This method basically relies on the assumption that the variables are mutually independent and identically distributed. However, this assumption seems to be quite restrictive as it eliminates the time dependence of variables and does not consider the nature and range of the dependence. Hiemstra and Jones (1994) modify the Baek and Brock (1992)'s test to allow the testing variables to exhibit short-term temporal dependence.

By defining the $m$-length lead vector of $Y_{t}$ by $Y_{t}^{m}$, and the $L y$-length and $L e$-length lag vectors of $Y_{t}$ and $E_{t}$, respectively, by $Y_{t-L y}^{L y}$ and $E_{t-L e}^{L e}$, we obtain the following representations (Hiemstra and Jones, 1994)

$$
\begin{gathered}
Y_{t}^{m}=\left(Y_{t}, Y_{t+1}, \ldots, Y_{t+m-1}\right) ; m=1,2, \ldots ; t=1,2, \ldots \\
Y_{t-L y}^{L y}=\left(Y_{t-L y}, Y_{t-L y+1}, \ldots, Y_{t-1}\right) ; L y=1,2, \ldots ; t=L y+1, L y+2, \ldots \\
E_{t-L e}^{L e}=\left(E_{t-L e}, E_{t-L e+1}, \ldots, E_{t-1}\right) ; L e=1,2, \ldots ; t=L e+1, L e+2, \ldots
\end{gathered}
$$

The definition of nonlinear Granger noncausality is then given by

$$
\begin{array}{r}
\operatorname{Pr}\left(\left\|Y_{t}^{m}-Y_{s}^{m}\right\|<\epsilon \mid\left\|Y_{t-L y}^{L y}-Y_{s-L y}^{L y}\right\|<\epsilon,\left\|E_{t-L e}^{L e}-E_{s-L e}^{L e}\right\|<\epsilon\right) \\
=\operatorname{Pr}\left(\left\|Y_{t}^{m}-Y_{s}^{m}\right\|<\epsilon \mid\left\|Y_{t-L y}^{L y}-Y_{s-L y}^{L y}\right\|<\epsilon\right),
\end{array}
$$

where $\operatorname{Pr}\{$.$\} is probability and \|\|$ is the maximum norm. If Eq. (2) holds for given values of $m, L y$ and $L e \geq 1$ and for $\epsilon>0$, then $\left\{E_{t}\right\}$ does not 
strictly Granger cause $\left\{Y_{t}\right\}$. Eq. (2) states that the conditional probability that two arbitrary $m$-length lead vectors of $\left\{Y_{t}\right\}$ are within distance $\epsilon$, given that the corresponding lagged $L_{y}$-length lag vectors of $\left\{Y_{t}\right\}$ are $\epsilon$-close, is the same when the $L_{e}$-length lag vectors of $E_{t}$ is $\epsilon$-close. It should be noted that for a bivariate observable series $\left(Y_{t}, X_{t}\right), t 1, \ldots, T$, the Hiemstra-Jones test consists of choosing a value of $\epsilon$ whose typical values are between 0.5 and 1.5 after normalizing the series to obtain unit variance, and to test subsequently Eq. (2) by estimating the conditional probabilities as ratios of unconditional probabilities.

Hiemstra and Jones (1994) show that under the Granger noncausality null hypothesis formulated by Eq. (2), the following statistic follows an asymptotic normal distribution as

$$
\sqrt{n}\left(\frac{C 1(m+L y, L e, \epsilon, n)}{C 2(m+L y, \epsilon, n)}-\frac{C 3(m+L y, \epsilon, n)}{C 4(L y, \epsilon, n)}\right) \sim A N\left(0, \sigma^{2}(m, L y, L e, \epsilon)\right),
$$

where $n=T+1-m-\max (L y, l e), C 1(m+L y, L e, \epsilon, n), C 2(m+L y, \epsilon, n)$, $C 3(m+L y, \epsilon, n)$, and $C 4(L y, \epsilon, n)$ are correlation-integral estimators of the point probabilities corresponding to the left hand side and right hand side of Eq. (2). It has been shown that this test has a very good power against a variety of nonlinear Granger causal and noncausal relations (Hiemstra and Jones, 1994; Ma and Kanas, 2000). The asymptotic variance $\sigma^{2}(m, L y, L e, \epsilon)$ is estimated using the theory of U-statistic for weakly dependent processes (Denker and Keller, 1983). ${ }^{3}$ The test statistic in Eq. (3) is applied to the estimated residual series from the bivariate VAR model. The null hypothesis is that $E_{t}$ does not nonlinearly strictly Granger cause $Y_{t}$, and Eq. (3) holds for all $m, L y, L e \geq 1$ and $\epsilon>0$. By removing a linear predictive power form a linear VAR model, any remaining incremental predictive power of one residual series for another can be considered as nonlinear predictive power (Baek and Brock, 1992).

\subsection{Kyrstou-Labys test}

Kyrstou and Labys (2006) adopt a different perspective to address the concept of nonlinear Granger causality by introducing the bivariate noisy Mackey-Glass (hereafter "M-G") model defined as follows

\footnotetext{
${ }^{3}$ For a complete and detailed derivation of the variance, see the appendix in Hiemstra and Jones (1994).
} 


$$
\begin{aligned}
& Y_{t}=\alpha_{11} \frac{Y_{t-\tau_{1}}}{1+Y_{t-\tau_{1}}^{c}}-\gamma_{11} Y_{t-1}+\alpha_{12} \frac{E_{t-\tau_{2}}}{1+E_{t-\tau_{2}}^{c_{2}}}-\gamma_{12} E_{t-1}+\epsilon_{t}, \\
& E_{t}=\alpha_{21} \frac{Y_{t-\tau_{1}}}{1+Y_{t-\tau_{1}}^{c}}-\gamma_{21} Y_{t-1}-\alpha_{22} \frac{E_{t-\tau_{2}}}{1+E_{t-\tau_{2}}^{c}}-\gamma_{22} E_{t-1}+\eta_{t},
\end{aligned}
$$

where $\epsilon_{t}$ and $\eta_{t} \sim N(0,1), t=\tau, \ldots, N, \tau=\max \left(\tau_{1}, \tau_{2}\right)$ and $Y_{0}, \ldots, Y_{\tau-1}$, $E_{0}, \ldots, E_{\tau-1}$ are given. The $\alpha_{i j}$, and $\gamma_{i j}$ are parameters to be estimated, $\tau_{i}$ are integer delays, and $c_{i}$ are constants which can be chosen via prior selection. In this respect, the best delays, $\tau_{1}$ and $\tau_{2}$, are selected on the basis of likelihood ratio tests and the Schwarz criterion. The model (4) is more appropriate than a simple VAR in case where dependency structures of time series are more complicated and cannot be taken into account by vector autoregressions. The M-G-based causality test is similar to the linear Granger causality test, except that the models fitted to the series are M-G processes. This test is performed by estimating the M-G model parameters under no constraint with ordinary least squares. To examine whether $E$ causes $Y$, another M-G model is estimated under the constraint $\alpha_{12}=0$ that reflects our null hypothesis. Such a constraint arises from the fact that when $E$ has a significant nonlinear effect on the current value of $Y$ in the model M-G, $\alpha_{12}$ must be significantly different from zero. Let $\hat{\vartheta}$ and $\hat{\nu}$ the residuals obtained respectively by the unconstrained and constrained bestfit M-G models. Thus, the corresponding sums of residuals squares can be defined as $S_{u}=\sum_{t=1}^{T} \hat{\vartheta}^{2}$ and $S_{c}=\sum_{t=1}^{T} \hat{\nu}^{2}$. Recall that $n_{u}=4$ is the number of free parameters in the M-G model and on the other side $n_{c}=1$ is the number of parameters required to be zero when estimating the restricted model. Obviously, the test statistic follows a Fisher distribution as

$$
\left.S_{F}=\frac{\left(S_{c}-S_{u}\right) / n_{c}}{S_{u} /\left(T-n_{u}-1\right)} \sim F_{(} n_{c}, T-n_{u}-1\right)
$$

where $S_{F}$ is the test statistic.

What we have just presented is called the Kyrtsou-Labys "symmetric" version of the causality between $E$ and $Y$. The "asymmetric" version of Kyrtsou-Labys test can be implemented by conditioning for positive or negative values of the causing series. To keep the matters tractable, suppose that we test, in model (4), whether nonnegative returns in the series $E$ cause the series $Y$. In this case, an observation $\left(E_{t}, Y_{t}\right)$ is included in the regression model only if $E_{t-\tau_{2}} \geq 0$. The same restricted set of observations is used to compute the model corresponding to the null hypothesis, i.e., $\alpha_{12}=0$. The 
procedure is then repeated with the order of the series reversed. That is, one can test whether positive returns in $Y$ cause $E$ and again with the subset of nonnegative returns. Note that conditioning in terms of causing series sign is not the only way to carry out an asymmetric causality. The sign conditioning is frequently chosen because it offers many advantages in practical relevance. Moreover, the nonpositivity, or respectively nonnegativity is not the only possible conditioning way as one can consider other events such as start/end of the week, price movement thresholds.

\section{Data and empiricals results}

\subsection{Data}

We use per capita GDP data, expressed in constant 2000 U.S. dollars, and per capita energy consumption data, expressed in terms of $\mathrm{kg}$ oil equivalent for the G7 countries. The data for Germany cover the period 1970-2010, while those for the remaining G7 countries span the period from 1960 to 2010. All the data are at annual frequency and obtained from the Word Development Indicators. Accordingly, we see important differences in energy consumption and GDP levels across the G7 countries. The average per capital energy consumption ranges from $2315.59 \mathrm{~kg}$ oil equivalent (Italy) to $7471.94 \mathrm{~kg}$ oil equivalent (United States). The average per capital GDP is comprised between US\$14070.35 (Italy) to US\$26823.79 (Japan). A close look at these series shows that per capital GDP generally increases with the per capital energy consumption, thus suggesting potential of causal interactions between these two variables.

Next, we check the stationarity of the variables by using two autoregressive unit root tests: the Augmented Dickey-Fuller (ADF) test, and the Phillips-Perron (PP) test. The results of unit root tests are reported in Table 3. The ADF and PP tests indicate that our variables are integrated of order one, but their first differences are stationary. However, since the ADF and $\mathrm{PP}$ unit root tests are known to suffer potentially severe finite sample power and size problems ${ }^{4}$, we also use three more efficient unit root tests to check the robustness of the ADF and PP results: the Elliott-Rothenberg-Stock

\footnotetext{
${ }^{4}$ De Jong et al. (1992) show that these tests have low power against the alternative hypothesis that the series is stationary with a large autoregressive root. Schwert (1989) documents severe size distortion in the direction of over-rejecting the null hypothesis of unit root when the time series has a large negative moving average root.
} 
(ERS) test of Elliot et al. (1996), the Dickey-Fuller test with GLS detrending procedure of $\mathrm{Ng}$ and Perron (2001), and the modified Phillips-Perron test of Perron and $\mathrm{Ng}$ (1996). We find evidence of nonstationarity for the variables in levels and stationarity for the variables in first differences.

Table 2: Summary of basic statistics.

\begin{tabular}{lcccccccc}
\hline & \multicolumn{3}{c}{ Energy consumption } & \multicolumn{3}{c}{ GDP } \\
\hline \multicolumn{2}{c}{ Mean } & \multicolumn{2}{c}{ SD } & \multicolumn{2}{c}{ Mean } & \multicolumn{2}{c}{ SD } \\
\hline Countries & Level & Difference & Level & Difference & Level & Difference & Level & Difference \\
\hline Canada & 7124.19 & 64.610 & 1144.95 & 201.11 & 17935.30 & 324.00 & 4983.07 & 386.48 \\
France & 3422.80 & 47.442 & 776.30 & 120.98 & 16443.13 & 307.49 & 4855.71 & 267.66 \\
Germany & 4241.76 & 4.8213 & 216.08 & 121.83 & 19015.73 & 335.27 & 4160.73 & 389.29 \\
Italy & 2315.59 & 40.374 & 623.87 & 82.682 & 14070.35 & 262.69 & 4581.36 & 308.72 \\
Japan & 3025.48 & 60.182 & 967.00 & 115.99 & 26823.79 & 631.30 & 10135.51 & 729.11 \\
UK & 3557.72 & 4.9807 & 224.97 & 102.73 & 18229.95 & 359.47 & 6073.53 & 446.39 \\
USA & 7471.94 & 31.661 & 680.19 & 201.13 & 25894.63 & 475.59 & 7709.26 & 548.36 \\
\hline
\end{tabular}

Notes: this table presents the main statistics of our sample data. The per capita GDP and per capita energy consumption data are expressed in constant 2000 U.S. dollars and in terms of $\mathrm{kg}$ oil equivalent, respectively. All the data are at annual frequency and obtained from the Word Development Indicators.

In the next subsection, we apply the nonlinear causality tests to the variables in first differences in order to detect the causal relationships between energy consumption and GDP.

\subsection{Results from the Hiemstra-Jones test}

Table 4 presents the empirical results from the Hiemstra-Jones nonlinear Granger causality test, based on the residuals of a VAR model. Similar to Hiemstra and Jones (1994), we fix the values for the head length $m=1$, the common lag lengths of 1 to 8 lags and a common scale parameter of $e=1.5$. We find evidence of a significant unidirectional nonlinear Granger causality running from energy consumption to GDP for the UK. The growth hypothesis investigated by the previous literature is thus supported by our data for the UK, meaning that the level of energy consumption, through affecting both directly and indirectly the industrial production, plays a crucial role in economic growth. In this scheme of things, a negative energy supply shock (i.e., sudden supply decreases) will adversely cause the economic growth to decline. Compared to previous studies, our result contrasts those of $\mathrm{Yu}$ and 
Table 3: Results of unit root tests

\begin{tabular}{|c|c|c|c|c|c|c|c|}
\hline & Canada & France & Germany & Italy & Japan & UK & USA \\
\hline \multirow{2}{*}{\multicolumn{8}{|c|}{ Unit root results for energy consumption }} \\
\hline & & & \multicolumn{5}{|c|}{$\mathrm{ADF}$} \\
\hline Level & -1.749 & -1.309 & -2.714 & -2.46 & -1.024 & -1.734 & -2.393 \\
\hline First difference & $-4.347^{* *}$ & $-7.447 * *$ & $-5.601 * *$ & $-3.285^{*}$ & $-5.013 * *$ & $-4.242^{* *}$ & $-4.549 * *$ \\
\hline \multicolumn{8}{|l|}{ PP } \\
\hline Level & -1.125 & -1.269 & -2.699 & -3.654 & -1.177 & -1.59 & -1.789 \\
\hline First difference & $-4.283^{* *}$ & $-7.456^{* *}$ & $-5.573 * *$ & $-5.955 * *$ & $-5.069 * *$ & $-6.733^{* *}$ & $-4.501 * *$ \\
\hline \multicolumn{8}{|l|}{ ERS } \\
\hline Level & 28.8537 & 32.8002 & 22.0803 & 99.2125 & 25.7197 & 24.5401 & 26.9517 \\
\hline First difference & $1.2112^{* *}$ & $3.764^{* *}$ & $1.2904^{* *}$ & $2.1358^{*}$ & $2.8298^{*}$ & $1.7419 * *$ & $1.2668^{* *}$ \\
\hline \multicolumn{8}{|l|}{ DF-GLS detrending } \\
\hline Level & -1.0516 & -1.0052 & -1.9725 & 0.0422 & -1.2323 & -1.283 & -1.371 \\
\hline First difference & $-4.3871 * *$ & $-7.3092^{* *}$ & $-4.1445^{* *}$ & $-2.8393^{* *}$ & $-2.3233^{*}$ & $-3.3753^{* *}$ & $-4.5602^{* *}$ \\
\hline \multicolumn{8}{|l|}{ Modified PP } \\
\hline Level & -0.9276 & -0.7813 & -1.5445 & 0.3212 & -1.0838 & -1.0611 & -1.1728 \\
\hline First difference & $-3.1577^{* *}$ & $-3.4717^{* *}$ & $-3.1809^{* *}$ & $-2.4607^{*}$ & $-2.0657^{*}$ & $-2.7483^{* *}$ & $-3.1973^{* *}$ \\
\hline \multicolumn{8}{|c|}{ Unit root results for GDP } \\
\hline \multicolumn{8}{|l|}{$\mathrm{ADF}$} \\
\hline Level & -0.9249 & -1.288 & -2.823 & -0.9105 & -0.5441 & -2.162 & -1.987 \\
\hline \multirow{2}{*}{\multicolumn{8}{|c|}{$\mathrm{PP}$}} \\
\hline & & & & & & & \\
\hline Level & -0.8119 & -0.8152 & -2.817 & -2.394 & -0.6491 & -1.862 & -2.315 \\
\hline First difference & $-5.008^{* *}$ & $-5.082 * *$ & $-5.931 * *$ & $-5.483^{* *}$ & $-5.126^{* *}$ & $-4.262^{* *}$ & $-5.205 * *$ \\
\hline \multicolumn{8}{|l|}{ ERS } \\
\hline Level & 84.4324 & 15.2086 & 7.6973 & 30.9447 & 28.2833 & 25.4143 & 12.2371 \\
\hline First difference & $1.2489^{* *}$ & $3.9822^{* *}$ & $1.4919^{* *}$ & $3.7469^{* *}$ & $1.194^{* *}$ & $2.3397^{*}$ & $4.0492^{*}$ \\
\hline \multicolumn{8}{|l|}{ DF-GLS detrending } \\
\hline Level & 0.803 & -1.4518 & 0.4133 & -0.327 & -1.1374 & -1.2139 & -2.0253 \\
\hline First difference & $-4.9143^{* *}$ & $-5.1694 * *$ & $-5.9157^{* *}$ & $-5.6664 * *$ & $-5.199 * *$ & $-2.4208^{*}$ & $-5.208 * *$ \\
\hline \multicolumn{8}{|l|}{ Modified PP } \\
\hline Level & 1.0274 & -1.4599 & -2.3866 & -0.2496 & -0.7696 & -1.3844 & -1.8648 \\
\hline First difference & $-3.2859 * *$ & $-3.3501^{*}$ & $-3.0398^{* *}$ & $-3.4264^{* *}$ & $-3.3267 * *$ & $-2.2956^{*}$ & $-3.3509^{*}$ \\
\hline
\end{tabular}

Notes: $* *$ and $*$ indicate significance at the $1 \%$ and $5 \%$ levels, respectively.

Choi (1985), Erol and Yu (1987), and Lee (2006), who find no causality between energy consumption and economic growth for the UK. Differently, Soytas and Sari (2006) find evidence of bidirectional causality for the UK from multivariate cointegration, error correction models and generalized variance decompositions, and.

Next, our results reveal significant bidirectional nonlinear causality between energy consumption and economic growth in four countries: Canada, France, Japan, and the USA. These causal feedback linkages are all positive and indicative of the fact that energy consumption and income are jointly determined. As a result, policymakers should have to pay close attention to any shocks to energy supply and economic growth. The empirical evidence is particularly strong in the case of France as the null hypotheses under consideration are rejected at the conventional levels for two lags (2 and 6) regarding the causality from energy to income, and for four lags $(2,4,6$, and 7) regarding the causality from income to energy. While the bidirectional energy-growth nexus was found for Canada (Ghali and El-Sakka, 2004; Soytas and Sari, 2006), for Japan (Erol and Yu, 1987; Soytas and Sari, 2006), 
and for the USA (Lee, 2006), our finding for France is new. Indeed, previous studies rather show evidence of unidirectional causality running from income to energy consumption (Lee, 2006), unidirectional causality running from energy consumption to GDP (Soytas and Sari, 2003, 2006) and no causality (Erol and $\mathrm{Yu}, 1987$ ).

For the remaining countries (Germany and Italy), no causal relationships are found between energy consumption and income. The validity of the neutrality hypothesis implies that for these countries, neither conservative nor expansive energy consumption policies will affect their economic growth. In addition, the fact that the economic growth is not linked to energy gives the said countries some degree of flexibility in planning the ecnomic development strategies.

\subsection{Results for the Kyrstou-Labys tests}

Table 5 shows the results for the parameter-prior selection in the M-Gbased Kyrstou-Labys tests. The first two columns indicate that the nonlinear effects between energy consumption and income can date at least from one year ago. For example, a 10-year lagged value of the US income can affect the current value of energy consumption, while a 2-year lagged value of the US energy consumption may still have significant effects on income. As to the causality from energy consumption to income, the relatively large values of the delay variable $\left(\tau_{2}\right)$ signify that an active and efficient energy management strategy is needed in order to promote economic growth.

The Kyrstou-Labys tests are then performed for each sample countries, based on the predetermined parameters in Table 5 . We firstly carry out the symmetric version of the test and report the results in Table 6 . Recall that this test allows to detect the nonlinear causality between the variables of interest (i.e., energy consumption and GDP in their first differences) without distinguishing the signs of their changes. Our findings show that there is no causality in both directions for three countries (Canada, Japan and the UK) at the conventional levels of confidence. Our results for Canada and Japan are thus not in line with those of Evol and Yu (1987) and Lee (2006), among others. In the United States, energy consumption is found to cause economic growth at the $5 \%$ level, but the causality from the opposite direction is not significant. Earlier studies including Stern (1993, 2000), Soytas and Sari (2006), and Bowden and Payne (2009) find similar results. The same pattern of unidirectional causality is observed for France, but with stronger statistical association. These results imply that the French and US economies 
Table 4: Hiemstra-Jones's nonlinear causality test

\begin{tabular}{|c|c|c|c|c|c|c|c|c|c|c|c|}
\hline \multicolumn{6}{|c|}{ Canada } & \multicolumn{6}{|c|}{ France } \\
\hline \multirow{2}{*}{$\begin{array}{l}\mathrm{H}_{0}: \\
\mathrm{Lags} \\
\end{array}$} & \multirow{2}{*}{$\frac{\mathrm{E} \text { do not cause }}{\mathrm{CS}}$} & \multirow{2}{*}{$\begin{array}{c}\text { e GDP } \\
\text { TVAL } \\
\end{array}$} & \multirow{2}{*}{$\begin{array}{l}\mathrm{H}_{0}: \\
\mathrm{Lags}\end{array}$} & \multicolumn{2}{|c|}{ DP do not cause $\mathrm{E}$} & \multicolumn{3}{|c|}{$\mathrm{H}_{0}: \mathrm{E}$ do not cause GDP } & \multicolumn{3}{|c|}{$\mathrm{H}_{0}:$ GDP do not cause $\mathrm{E}$} \\
\hline & & & & CS & TVAL & Lags & CS & TVAL & Lags & $\mathrm{CS}$ & TVAL \\
\hline 1 & -2.0789 & -13.311 & 1 & -0.3073 & -1.9681 & 1 & -0.7459 & -4.7762 & 1 & -0.9234 & -5.9132 \\
\hline 2 & 0.6477 & $4.1476^{*}$ & 2 & -0.9016 & -5.773 & 2 & 4.5825 & $29.3429^{* *}$ & 2 & 0.3531 & $2.2613^{*}$ \\
\hline 3 & 0.1255 & 0.8040 & 3 & -0.9988 & -6.3957 & 3 & -0.1367 & -0.8759 & 3 & 0.0361 & 0.2311 \\
\hline 4 & 0.0000 & 0.0000 & 4 & -0.8978 & -5.7489 & 4 & -0.1431 & -0.9162 & 4 & 0.8627 & $5.5240^{* *}$ \\
\hline 5 & 0.0000 & 0.0000 & 5 & -0.6147 & -3.9366 & 5 & -1.0541 & -6.7497 & 5 & -1.2536 & -8.0274 \\
\hline 6 & 0.0000 & 0.0000 & 6 & 9.6464 & $61.767^{* *}$ & 6 & 0.80602 & $5.1610^{* *}$ & 6 & 0.9586 & $6.1380^{* *}$ \\
\hline 7 & -0.6173 & -3.9527 & 7 & 2.0512 & $13.134 * *$ & 7 & 0.0000 & 0.0000 & 7 & 0.3467 & $2.2202^{*}$ \\
\hline 8 & -1.2216 & -7.8222 & 8 & 0.0000 & 0.0000 & 8 & 0.0000 & 0.0000 & 8 & 0.0056 & 0.0364 \\
\hline \multicolumn{6}{|c|}{ Germany } & \multicolumn{6}{|c|}{ Italy } \\
\hline \multicolumn{2}{|c|}{$\mathrm{H}_{0}: \mathrm{E}$ do not cause } & e GDP & \multicolumn{3}{|c|}{$\mathrm{H}_{0}$ : GDP do not cause $\mathrm{E}$} & \multicolumn{3}{|c|}{$\mathrm{H}_{0}$ : E do not cause GDP } & \multicolumn{3}{|c|}{ GDP do not cause E } \\
\hline Lags & $\mathrm{CS}$ & TVAL & Lags & $\mathrm{CS}$ & TVAL & Lags & $\mathrm{CS}$ & TVAL & Lags & $\mathrm{CS}$ & TVAL \\
\hline 1 & -0.3489 & -1.9427 & 1 & -0.7990 & -4.4487 & 1 & -0.8785 & -5.6257 & 1 & -0.6193 & -3.9657 \\
\hline 2 & -2.4369 & -13.568 & 2 & -3.3417 & -18.606 & 2 & -0.5687 & -3.6417 & 2 & -0.6183 & -3.9594 \\
\hline 3 & -0.2959 & -1.6480 & 3 & -0.0009 & -0.0052 & 3 & -0.6246 & -3.999 & 3 & 0.14534 & 0.9306 \\
\hline 4 & -0.5667 & -3.1553 & 4 & -0.0972 & -0.5413 & 4 & -0.6345 & -4.0628 & 4 & -0.2004 & -1.2833 \\
\hline 5 & -0.4532 & -2.5236 & 5 & -0.1555 & -0.86611 & 5 & -0.7049 & -4.5136 & 5 & -0.2249 & -1.4404 \\
\hline 6 & -0.5367 & -2.9885 & 6 & -0.3005 & -1.6731 & 6 & -0.9914 & -6.3484 & 6 & -0.32462 & -2.0786 \\
\hline 7 & -0.7673 & -4.2724 & 7 & -0.4296 & -2.3919 & 7 & -1.0279 & -6.5823 & 7 & -0.3763 & -2.4099 \\
\hline 8 & -0.8204 & -4.5682 & 8 & -0.25 & -1.3919 & 8 & -1.6119 & -10.321 & 8 & -0.7786 & -4.9855 \\
\hline \multicolumn{6}{|c|}{ Japan } & \multicolumn{6}{|c|}{ UK } \\
\hline \multicolumn{3}{|c|}{$\mathrm{H}_{0}: \mathrm{E}$ do not cause GDP } & \multicolumn{3}{|c|}{$\mathrm{H}_{0}$ : GDP do not cause $\mathrm{E}$} & \multicolumn{3}{|c|}{$\mathrm{H}_{0}: \mathrm{E}$ do not cause GDP } & \multicolumn{3}{|c|}{$\mathrm{H}_{0}:$ GDP do not cause $\mathrm{E}$} \\
\hline Lags & CS & TVAL & Lags & CS & TVAL & Lags & CS & TVAL & Lags & CS & TVAL \\
\hline 1 & 0.1895 & 1.2139 & 1 & -1.2792 & -8.1914 & 1 & -0.6290 & -4.0276 & 1 & -0.6730 & -4.3098 \\
\hline 2 & -0.1466 & -0.9391 & 2 & -0.2648 & -1.6958 & 2 & -0.0755 & -0.4838 & 2 & -3.8681 & -24.768 \\
\hline 3 & 0.2658 & $1.7019 *$ & 3 & 0.3608 & $2.3107^{*}$ & 3 & -0.9426 & -6.0360 & 3 & -0.8590 & -5.5003 \\
\hline 4 & 0.0000 & 0.0000 & 4 & -0.1068 & -0.6843 & 4 & 1.1401 & $7.3006^{* *}$ & 4 & -0.2615 & -1.6749 \\
\hline 5 & 0.0000 & 0.0000 & 5 & -0.1196 & -0.7663 & 5 & 0.6667 & $4.2695^{*}$ & 5 & -0.4577 & -2.9311 \\
\hline 6 & 0.0000 & 0.0000 & 6 & 0.0000 & 0.0000 & 6 & 0.5515 & $3.5313^{*}$ & 6 & -0.5398 & -3.4564 \\
\hline 7 & 0.0000 & 0.0000 & 7 & 0.0000 & 0.0000 & 7 & 0.0549 & 0.3518 & 7 & -0.3652 & -2.3385 \\
\hline 8 & 0.0000 & 0.0000 & 8 & 0.0000 & 0.0000 & 8 & 0.0796 & 0.5101 & 8 & -0.5401 & -3.4589 \\
\hline & & & & & & & & & & & \\
\hline $\mathrm{H}_{0}:$ & E do not cause & e GDP & $\mathrm{H}_{0}:$ & $\mathrm{P}$ do no & cause $\mathrm{E}$ & & & & & & \\
\hline Lags & $\mathrm{CS}$ & TVAL & Lags & $\mathrm{CS}$ & TVAL & & & & & & \\
\hline 1 & -0.4946 & -3.1670 & 1 & -0.6047 & -3.8723 & & & & & & \\
\hline 2 & -0.8363 & -5.3550 & 2 & -0.1519 & -0.9729 & & & & & & \\
\hline 3 & -94.832 & -607.226 & 3 & 315.54 & $99.524^{* *}$ & & & & & & \\
\hline 4 & 0.3765 & $2.4111^{*}$ & 4 & -0.0407 & -0.2606 & & & & & & \\
\hline 5 & -1.5380 & -9.8483 & 5 & -0.7683 & -4.9196 & & & & & & \\
\hline 6 & 0.1768 & 1.1326 & 6 & 0.0000 & 0.0000 & & & & & & \\
\hline 7 & 0.0788 & 0.5050 & 7 & 0.0000 & 0.0000 & & & & & & \\
\hline 8 & 0.07311 & 0.4681 & 8 & -0.5440 & -3.4837 & & & & & & \\
\hline
\end{tabular}

Notes: E and Y indicate energy consumption and GDP, respectively. CS and TVAL are respectively the difference between the two conditional probabilities, and the standardized test statistic. "lags" denotes the number of lags in the residual series used in the test. ** and * indicate significance at the $1 \%$ and $5 \%$ levels, respectively.

depend, to a large extent, on energy and that energy consumption is likely to invigorate income. For Germany, we observe a weak causality relation running from income to energy consumption, indicating that this country has a less energy-dependent economy. This finding contrasts with that of Soytas and Sari (2003), but supports that of Erol and Yu (1987), Lee (2006), and Soytas and Sari (2006).

Whether the direction of changes in the studied series has a significant effect on their causal relationships can be examined by the asymmetric version of the Kyrstou-Labys test. We report the results in Tables 7 and 8 . The exponent $p$ (respectively, $n$ ) indicate that only positive (respectively, 
Table 5: Parameter-prior selection in the M-G model

\begin{tabular}{ccccc}
\hline & $\tau_{1}$ & $\tau_{2}$ & $c_{1}$ & $c_{2}$ \\
\hline USA & 10 & 2 & 1 & 2 \\
UK & 1 & 10 & 3 & 4 \\
Germany & 10 & 7 & 10 & 4 \\
Japan & 2 & 10 & 2 & 10 \\
France & 9 & 10 & 5 & 1 \\
Italy & 10 & 1 & 1 & 10 \\
Canada & 10 & 6 & 10 & 2 \\
\hline
\end{tabular}

Notes: This table reports the results for the parameter-prior selection. $\tau_{1}$ and $\tau_{2}$ are the optimal integrer delay variables for the causality from income to energy consumption, and for the causality from energy consumption to income, respectively. $c_{1}$ and $c_{2}$ are the power of the lagged values of income and energy consumption, respectively.

Table 6: Kyrstou-Labys nonlinear causality test (symmetric case)

\begin{tabular}{lcr}
\hline Relation $(A \rightarrow B)$ & F-statistic & Probability \\
$E_{U S A} \rightarrow Y_{U S A}$ & 6.7902 & 0.0150 \\
$Y_{U S A} \rightarrow E_{U S A}$ & 0.9053 & 0.3501 \\
$E_{U K} \rightarrow Y_{U K}$ & 0.2608 & 0.6139 \\
$Y_{U K} \rightarrow E_{U K}$ & 0.5628 & 0.4599 \\
$E_{\text {Germany }} \rightarrow Y_{\text {Germany }}$ & 0.0693 & 0.7957 \\
$Y_{\text {Germany }} \rightarrow E_{\text {Germany }}$ & 3.2855 & 0.0887 \\
$E_{\text {Japan }} \rightarrow Y_{\text {Japan }}$ & 0.0572 & 0.8129 \\
$Y_{\text {Japan }} \rightarrow E_{\text {Japan }}$ & 0 & 1 \\
$E_{\text {France }} \rightarrow Y_{\text {France }}$ & 15.8266 & 0.0005 \\
$Y_{\text {France }} \rightarrow E_{\text {France }}$ & 1.1388 & 0.2957 \\
$E_{\text {Italy }} \rightarrow Y_{\text {Italy }}$ & 4.1357 & 0.0523 \\
$Y_{\text {Italy }} \rightarrow E_{\text {Italy }}$ & 0 & 1 \\
$E_{\text {Canada }} \rightarrow Y_{\text {Canada }}$ & 0.4854 & 0.4922 \\
$Y_{\text {Canada }} \rightarrow E_{\text {Canada }}$ & 2.3932 & 0.1339
\end{tabular}

Notes: we consider the null hypothesis that A does not cause B. 
Table 7: Kyrstou-Labys nonlinear causality test (asymmetric case for positive changes in the causing variables)

\begin{tabular}{lcr}
\hline Relation $(A \rightarrow B)$ & F-statistic & Probability \\
$E_{U S A}^{p} \rightarrow Y_{U S A}$ & 11.8988 & 0.0014 \\
$Y_{U S A}^{p} \rightarrow E_{U S A}$ & 0.0131 & 0.9094 \\
$E_{U K}^{p} \rightarrow Y_{U K}$ & 1.5821 & 0.2165 \\
$Y_{U K}^{p} \rightarrow E_{U K}$ & 0.8513 & 0.3623 \\
$E_{\text {Germany }}^{p} \rightarrow Y_{\text {Germany }}$ & 1.3129 & 0.2623 \\
$Y_{\text {Germany }}^{p} \rightarrow E_{\text {Germany }}$ & 0.0029 & 0.9576 \\
$E_{\text {Japan }}^{p} \rightarrow Y_{\text {Japan }}$ & 6.9564 & 0.0123 \\
$Y_{\text {Japan }}^{p} \rightarrow E_{\text {Japan }}$ & 0 & 1 \\
$E_{\text {France }}^{p} \rightarrow Y_{\text {France }}$ & 34.4100 & 0 \\
$Y_{\text {France }}^{p} \rightarrow E_{\text {France }}$ & 0.9631 & 0.3330 \\
$E_{\text {Italy }}^{p} \rightarrow Y_{\text {Italy }}$ & 7.5184 & 0.0095 \\
$Y_{\text {Italy }}^{p} \rightarrow E_{\text {Italy }}$ & 0 & 1 \\
$E_{\text {Canada }}^{p} \rightarrow Y_{\text {Canada }}$ & 0.1038 & 0.7491 \\
$Y_{\text {Canada }}^{p} \rightarrow E_{\text {Canada }}$ & 0.3701 & 0.5468 \\
\hline
\end{tabular}

Notes: we consider the null hypothesis that A does not cause B.

Table 8: Kyrstou-Labys nonlinear causality test (asymmetric case for negative changes in the causing variables)

\begin{tabular}{lcr}
\hline Relation $(A \rightarrow B)$ & F-statistic & Probability \\
$E_{U S A}^{n} \rightarrow Y_{U S A}$ & 4.1866 & 0.0481 \\
$Y_{U S A}^{n} \rightarrow E_{U S A}$ & 0.0720 & 0.7900 \\
$E_{U K}^{n} \rightarrow Y_{U K}$ & 4.0388 & 0.0520 \\
$Y_{U K}^{n} \rightarrow E_{U K}$ & 0.5498 & 0.4632 \\
$E_{\text {Germany }}^{n} \rightarrow Y_{\text {Germany }}$ & 0.2831 & 0.5992 \\
$Y_{\text {Germany }}^{n} \rightarrow E_{\text {Germany }}$ & 217.7047 & 0 \\
$E_{\text {Japan }}^{n} \rightarrow Y_{\text {Japan }}$ & 1.2392 & 0.2730 \\
$Y_{\text {Japan }}^{n} \rightarrow E_{\text {Japan }}$ & 0 & 1 \\
$E_{\text {France }}^{n} \rightarrow Y_{\text {France }}$ & 0.0795 & 0.7796 \\
$Y_{\text {France }}^{n} \rightarrow E_{\text {France }}$ & 0 & 1 \\
$E_{\text {Italy }}^{n} \rightarrow Y_{\text {Italy }}$ & 0.0097 & 0.9222 \\
$Y_{\text {Italy }}^{n} \rightarrow E_{\text {Italy }}$ & 0 & 1 \\
$E_{\text {Canada }}^{n} \rightarrow Y_{\text {Canada }}$ & 7.0055 & 0.0120 \\
$Y_{\text {Canada }}^{n} \rightarrow$ E Eanada & 111.0337 & 0 \\
\hline
\end{tabular}

Notes: we consider the null hypothesis that A does not cause B. 
negative) values of the causing series were selected. Table 7 shows that there is a significant unidirectional causality at the $1 \%$ and $5 \%$ levels, running from positive changes in energy consumption to changes in GDP (France, Italy, Japan, and the USA). On the other hand, energy consumption reductions significantly cause GDP changes in Canada and the USA (at the 5\% level), and in the UK (at the 10\% level). By contrast, the causality from GDP reductions to changes in energy consumption is significant for Canada and Germany. Taken together, negative changes in either GDP or energy consumption provoke adjustments in the value of the other variable.

\section{Conclusion}

In this paper, we investigated the causal relationships between energy consumption and income for the G7 countries. Our approach differs from the majority of previous studies in that we focus on the nonlinear patterns of the possible underlying interactions between the two variables of interest. More specifically, we draw the empirical evidence from two powerful nonlinear Granger causality tests, proposed by Hiemstra and Jones (1994), and Kyrstou and Labys (2006). Using per capita GDP and energy consumption data, our results appear to be very country-specific, and sometimes mixed between the two nonlinear tests we consider. For example, while the nonparametric Hiemstra-Jones test shows evidence of a bidirectional relationship between energy consumption and income for France, the symmetric KyrstouLabys test concludes on the existence of a unidirectional causality from energy consumption to income. The results for Germany are also conflicting as the Hiemstra-Jones test and the symmetric Kyrstou-Labys test detect, respectively, no causality and a unidirectional causality from income to energy consumption. It is important to note that the presence of bidirectional nonlinear relationships we found for France was never evidenced in previous studies. Finally, we show that the directions of changes in the energy consumption and income matter for their causal interactions and that they should be considered while making policy decisions to balance governments' expenditures and revenues.

\section{References}

[1] Abosedra, S., Baghestani, H., 1989. New evidence on the causal relationship between United States energy consumption and gross national product. Journal of Energy Development 14, 285-292. 
[2] Akarca, A.T., Long, T.V., 1980. On the relationship between energy and GNP: a reexamination. Journal of Energy Development 5, 326-331.

[3] Akinlo, A.E., 2008. Energy consumption and economic growth: Evidence from 11 Sub- Sahara African countries. Energy Economics 30(5), 2391-2400.

[4] Aloui, C., Nguyen, D.K., Njeh, H., 2012. Assessing the impacts of oil price fluctuations on stock returns in emerging markets. Economic Modelling 29, 2686-2695.

[5] Ang, J.B., 2008. Economic development, pollutant emissions and energy consumption in Malaysia. Journal of Policy Modeling 30, 271-278.

[6] Arouri, M.H., Nguyen, D.K., 2010. Oil prices, stock markets and portfolio investment: evidence from sector analysis in Europe over the last decade. Energy Policy 38, 4528-4539.

[7] Baek, E., Brock, W., 1992. A general test for granger causality: bivariate model. Technical Report, Iowa State University and University of Wisconsin, Madison.

[8] Balke, N.S., Brown, S.P.A., Yücel, M.K., 2002. Oil price shocks and the U.S. economy: where does the asymmetry originate? Energy Journal $23,27-52$.

[9] Belloumi, M., 2009. Energy consumption and GDP in Tunisia: Cointegration and causality analysis. Energy Policy 37, 2745-2753.

[10] Bowden, N., Payne, J.E., 2009. The causal relationship between US energy consumption and real output: a disaggregated analysis. Journal of Policy Modeling 31, 180-188.

[11] Cheng, B., 1995. An investigation of cointegration and causality between energy consumption and economic growth. Journal of Energy Development $21,73-84$.

[12] Chiou-Wei, S.Z., Chen, C-F., Zhu, Z., 2008. Economic growth and energy consumption revisited: evidence from linear and nonlinear Granger causality. Energy Economics 30, 3063-3076. 
[13] Cologni, A., Manera, M., 2008. Oil prices, inflation and interest rates in a structural cointegrated VAR model for the G-7 countries. Energy Economics 38, 856-888.

[14] Cologni, A., Manera, M., 2009. The asymmetric effects of oil shocks on output growth: a Markov-switching analysis for the G-7 countries. Economic Modelling 26, 1-29.

[15] De Jong, D.N., Nankervis, J.C., Savin, N.E., Whiteman, C.H., 1992. The power problems of unit root tests in time series with autoregressive errors. Journal of Econometrics 53, 323-343.

[16] Denker, M., Keller, G., 1983. On U-statistics and von-Mises statistics for weakly dependent processes. Zeitschrift fur Wahrscheinlichkeitstheorie und Verwandte Gebiete 64, 505-522.

[17] Elliot, G., Rothenberg, T., and Stock, J.H., 1996. Efficient tests for an autoregressive unit root. Econometrica, 64, 813-836.

[18] Erdal, G., Erdal, H., Esengun, K., 2008. The causality between energy consumption and economic growth in Turkey. Energy Policy 36 (10), $3838-3842$.

[19] Erol, U., Yu, E.S.H., 1987. On the causal relationship between energy and income for industrializing countries. Journal of Energy and Development $13,113-122$.

[20] Fayyad, A., Daly, K., 2011. The impact of oil price shocks on stock market returns: comparing GCC countries with the UK and USA. Emerging Markets Review 12, 61-78.

[21] Francis, B. M., Moseley, L., Iyare, S. O., 2010. Energy consumption and projected growth in selected caribbean countries. Energy Economics 29(6), 1224-1232.

[22] Ghali, K.H., El-Sakka, M.I.T., 2004. Energy use and output growth in Canada: a multivariate cointegration analysis. Energy Economics 26, $225-238$.

[23] Glasure, Y.U., 2002. Energy and national income in Korea: further evidence on the role of omitted variables. Energy Economics. 24, 355365. 
[24] Granger, C.W.J., 1969. Investigating causal relations by econometric models and cross-spectral methods. Econometrica 37, 424-438.

[25] Halicioglu, F., 2009. An econometric study of CO2 emissions, energy consumption, income and foreign trade in Turkey. Energy Policy 37, 699-702.

[26] Hamilton, J.D., 1983. Oil and the macroeconomy since World War II. Journal of Political Economy 91, 228-248.

[27] Hamilton, J.D., 2003. What is an oil shock? Journal of Econometrics 113, 363-398.

[28] Hiemstra, C., Jones, J.D., 1994. Testing for linear and nonlinear Granger causality in the stock price-volume relation, Journal of Finance 49, 16391664 .

[29] Ho, C.Y., Siu, K.W., 2007. A dynamic equilibrium of electricity consumption and GDP in Hong Kong: and empirical investigation, Energy Policy 35(4), 2507-2513.

[30] Hooker, M.A., 1996. What happened to the oil price-macroeconomy relationship? Journal of Monetary Economics 38, 195-213.

[31] Hristu-Varsakelis, D., Kyrtsou, C., 2008. Evidence for nonlinear asymmetric causality in us inflation, metal, and stock returns. Discrete Dynamics in Nature and Society, Article ID 138547, 7 pages, doi:10.1155/2008/138547.

[32] Huang, B.N., Hwang, M.J., Yang, C.W., 2008. Does more energy consumption bolster economic growth? An application of the nonlinear threshold regression model. Energy Policy 36(2). 755-767.

[33] Jammazi, R., Aloui, C., 2010. Wavelet decomposition and regime shifts: Assessing the effects of crude oil shocks on stock market returns. Energy Policy 38, 1415-1435.

[34] Jones, C.M., Kaul, G., 1996. Oil and the stock markets. Journal of Finance 51, 463-491.

[35] Kraft, J., Kraft, A., 1978. On the relationship between energy and GNP. Journal of Energy and Development 3, 401-403. 
[36] Kyrtsou, C, Labys, W.C., 2006. Evidence for chaotic dependence between US inflation and commodity prices. Journal of Macroeconomics 28, 256-266.

[37] Kyrtsou, C, Labys, W.C., 2007. Detecting positive feedback in multivariate time series: the case of metal prices and US inflation. Physica A 377, 227-229.

[38] Lardic, S., Mignon, V., 2008. Oil prices and economic activity: an asymmetric cointegration approach, Energy Economics 30, 847-855.

[39] Lee, C.C., 2006. The causality relationship between energy consumption and GDP in G-11 countries revisited. Energy Policy 34, 1086-1093.

[40] Lee, C.C., Chang, C.P., 2007. Energy consumption and GDP revisited: A panel analysis of developed and developing countries. Energy Economics, 29(6), 1206-1223.

[41] Ma, Y., Kanas, A., 2000. Testing nonlinear relationship among fundamentals and exchange rates in the ERM. Journal of International Money and Finance 19, 135-152.

[42] Mehrara, M., 2007. Energy consumption and economic growth: the case of oil exporting countries. Energy Policy 35 (5), 2939-2945.

[43] Mork, K.A., 1989. Oil and the macroeconomy when prices go up and down: an extension of Hamilton's results. Journal of Political Economy 97, 740-744.

[44] Ng, S., Perron, P., 2001. Lag length selection and the construction of unit root tests with good size and power. Econometrica 69, 1519-1554.

[45] Oh, W., Lee, K., 2004. Causal relationship between energy consumption and GDP revisited: the case of Korea 1970-1999. Energy Economics 26, 51-59.

[46] Ozturk, I., 2010. A literature survey on energy-growth nexus. Energy Policy 38, 340-349.

[47] Park, J., Ratti, R.A., 2008. Oil price shocks and stock markets in the U.S. and 13 European countries. Energy Economics 30, 2587-2608. 
[48] Payne, J.E., 2009. On the dynamics of energy consumption and output in the US. Applied Energy 86, 575-577.

[49] Payne, J.E., 2010. A survey of the electricity consumption-growth literature. Applied Energy 87, 723-732.

[50] Perron, P., Ng, S., 1996. Useful modifications to some unit root tests with dependent errors and their local asymptotic properties. Review of Economic Studies 63, 435-63.

[51] Rahman, S., Serletis, A., 2010. The asymmetric effects of oil price and monetary policy shocks: A nonlinear VAR approach, Energy Economics $32,1460-1466$.

[52] Sadorsky, P., 2001. Risk factors in stock returns of Canadian oil and gas companies. Energy Economics 23, 17-28.

[53] Saikkonen, P., 2005. Stability results for nonlinear error correction models. Journal of Econometrics 127, 69-81.

[54] Schwert, G.W., 1989. Tests for unit roots: a Monte Carlo investigation. Journal of Business and Economic Statistics 2, 147-159.

[55] Soytas, U., Sari, R., 2003. Energy consumption and GDP: causality relationship in G7 countries and emerging markets. Energy Economics $25,33-37$.

[56] Soytas, U., Sari, R., 2006. Energy consumption and income in G7 countries. Journal of Policy Modeling 28, 739-750.

[57] Stern, D.I., 1993. Energy and economic growth in the USA: a multivariate approach. Energy Economics 15, 137-150.

[58] Stern, D.I., 2000. A multivariate cointegration analysis of the role of energy in the US macroeconomy. Energy Economics 22, 267-283.

[59] Wolde-Rufael, Y., 2004. Disaggregated industrial energy consumption and GDP: The case of Shanghai 1952- 1999. Energy Economics 26, 6975 .

[60] Yu, E.S.H., Hwang, B.K., 1984. The relationship between energy and GNP: further results. Energy Economics 6, 186-190. 
[61] Yu, E.S.H., Choi, J.Y., 1985. The causal relationship between energy and GNP: an international comparison. Journal of Energy and Development $10,249-272$.

[62] Yu, E.S.H., Jin, J.C., 1992. Cointegration tests of energy consumption, income, and employment. Resources and Energy 14, 259-266.

[63] Zamani, M., 2007. Energy consumption and economic activities in Iran. Energy Economics 29, 1135-1140.

[64] Zhang, D., 2008. Oil shock and economic growth in Japan: a nonlinear approach. Energy Economics 30, 2374-2390.

[65] Zhang, X.P., Cheng, X.M., 2009. Energy consumption, carbon emissions and economic growth in China. Ecological Economics 68, 2706-2712. 